\title{
POTENTIAL ROLE OF SELECTED BIOMARKERS FOR PREDICTING THE PRESENCE AND EXTENT OF CORONARY ARTERY DISEASE
}

\author{
Martin Griva $^{a *}$, Robert Naplava ${ }^{\mathrm{a}}$, Milada Spendlikova ${ }^{\mathrm{b}}$, Jiri Jarkovskyc, \\ Ota Hlinomaz ${ }^{\mathrm{d}}$, Cestmir Cihalik ${ }^{\mathrm{a}}$
}

\author{
a Department of Internal Medicine, T. Bata's Hospital, Zlin, Czech Republic \\ b Immunologic laboratory, T. Bata's Hospital, Zlin \\ c Institute of Biostatistics and Analyses, Faculty of Medicine and the Faculty of Science of the Masaryk University, Brno, \\ Czech Republic \\ d 1st Department of Internal Medicine - Cardioangiology, St. Anne's University Hospital, Brno \\ E-mail:m.griva@seznam.cz
}

Received: March 28, 2010; Accepted with revision: June 22, 2010

Key words: Coronary artery disease/Macrophage chemoattractant protein-1/Matrix-metalloproteinase-3/Soluble CD40 ligand/Soluble tumour necrosis factor receptor-2/SYNTAX score

Introduction. Since atherosclerosis may in part be an inflammatory disease, circulatory factors related to inflammation may be predictors of coronary artery disease. The aim of this study was to evaluate the association between the level of some circulating biomarkers and the extent of coronary artery disease.

Methods. Blood samples were taken from 128 patients with stable forms of coronary heart disease. Macrophage chemoattractant protein-1 (MCP-1), matrix-metalloproteinase-3 (MMP-3), soluble CD40 ligand (sCD40L) and soluble tumour necrosis factor receptor-2 (sTNFR2) were measured by ELISA. Coronary angiography and grading with the SYNTAX score followed.

Results. There was no significant interdependence of circulating MCP-1, sCD40L, sTNFR2 levels and SYNTAX score. MMP-3 levels were significantly different in subgroup with coronary artery disease (SYNTAX score > 0): $38.1 \mu \mathrm{g} / 1(13.6 ; 84.1)$ and subgroup without coronary artery disease (SYNTAX score = 0): 20.4 $\mu \mathrm{g} / 1(13.1 ; 82.8)$, $\mathrm{p}=0.001$. According to the Spearman correlation coefficient there was significant association between MMP-3 level and SYNTAX score $(0.358, \mathrm{a}=0.05)$.

Conclusions. Our data suggest association between the extent of coronary artery disease and circulating MMP-3. We failed to demonstrate any association with the other investigated biomarkers.

\section{INTRODUCTION}

Atherosclerosis is the main cause of myocardial ischemia. In 2008, $17.9 \%$ of all deaths in the Czech Republic were due to chronic ischaemic heart disease ${ }^{1}$. These patients risk acute coronary syndrome, progressive heart failure and sudden cardiac death. The most important prognostic value for patients with stable forms of coronary heart disease is left ventricular function, the complexity of the coronary artery disease and serious myocardial ischemia. Coronary angiography remains elementary for the evaluation of coronary disease. However,

\footnotetext{
ABBREVIATIONS

MCP-1 - Monocyte chemoattractant protein-1

MMPs - Matrix-metalloproteinases

MMP-3 - Matrix-metalloproteinase-3

TIMPs - Tissue inhibitors of metalloproteinases

sCD40L - Soluble CD40 ligand

sTNFR2 - Soluble tumour necrosis factor receptor-2

CAD - Coronary artery disease

CHD - Coronary heart disease

ELISA - Enzyme-linked immunosorbent assay
}

more recently coronary CT angiography has become more important in that process ${ }^{2}$. For determination of the complexity of coronary artery disease there has been developed an angiographic grading tool - the SYNTAX score. This helps to identify the potential risk for revascularization and aids choosing the optimal revascularisation strategy $^{3}$.

Since atherosclerosis may in part be an inflammatory disease, circulatory factors related to inflammation could be predictors of coronary artery disease. The aim of this study was to evaluate the association between the level of some circulating biomarkers and the extent of coronary artery disease.

\section{MATERIALS AND METHODS}

A cohort of 128 subjects was recruited by random selection of patients with stable forms of coronary heart disease (stable angina pectoris, silent ischemia, unclear chest pain) who were sent to our cardiology department. Exclusion criteria, were acute coronary syndrome, renal insufficiency, systemic autoimmune disease, chronic or acute inflammation. The clinical characteristics of pa- 
tients are summarized in Table 1 , updated treatment in Table 2.

Blood samples were drawn into plastic tubes without anticoagulant and immediately spun at $1,500 \times \mathrm{g}$ for $10 \mathrm{~min}$ (centrifuge MPW 350, Med. Instruments, Spoldzielnia Pracy, Warszawa, Poland) at room temperature. Serum was immediately isolated and stored at $-20^{\circ} \mathrm{C}$ until analysed. Specimens were not repeatedly defrosted before analysis. Serum concentrations of MCP-1, MMP3, sCD40L and sTNFR2 were measured concurrently by ELISA standard CE method (Bender MedSystems, eBioscience Corporation, San Diego, California, USA) according to the recent manufacturer recommendations. The minimal sensitivity and precision of the method are $2.31 \mathrm{ng} / \mathrm{l}$, variation coefficient $(\mathrm{CV})=6.2 \%$ for $\mathrm{MCP}-1$; $0.06 \mu \mathrm{g} / \mathrm{l}, \mathrm{CV}=5.4 \%$ for MMP-3; $0.062 \mu \mathrm{g} / \mathrm{l}, \mathrm{CV}=10.7 \%$ for sCD40L; $0.053 \mu \mathrm{g} / 1, \mathrm{CV}=12.9 \%$ for sTNFR2 in accordance with the precision data provided. The absorption at $450 \mathrm{~nm}$ was used for photometric assay (spectrophotometer Spectra Shell, SLT Labinstrument, Austria).

For HbA1c assessment,blood samples were drawn into plastic tubes containing tripotassium EDTA, blood was processed on the day of withdrawal. For standard biochemical assessments the serum was processed on the day of blood withdrawal. The standard technique of the local laboratory was used.

Coronary angiography followed. The findings were evaluated by two independent experienced interventional cardiologists unfamiliar with the biochemical analysis results. No quantitative coronary analysis tool nor intravascular imaging method were used. SYNTAX score was assessed using original freeware.

Standard descriptive statistics were adopted for the analysis. Continuous variables were described by means of medians and $5-95^{\text {th }}$ percentile; categorical variables were described using percentages in categories. The statistical significance of differences in continuous variables between groups was analysed using the Mann-Whitney $\mathrm{U}$ test; Fisher exact test was applied for analysis of the relationship between binary variables. Statistical dependence between two variables was assessed by Spearman's rank correlation coefficient and means of ML Chi-square test. $\alpha=0.05$ was adopted as the chosen level of statistical significance in all tests.

\section{RESULTS}

Circulating MCP-1 and MMP-3 levels significantly differed between subgroups with and without diabetes mellitus (Table 1). Gender variability of biomarker levels was investigated. MCP-1, MMP-3 and sTNFR2 significantly differed between male and female subgroups (Table 3 ).

The entire patient group was divided into two subgroups: subjects with coronary artery disease (SYNTAX score $>0$ ) and subjects without significant coronary artery stenosis (SYNTAX score $=0$ ). Biomarker levels in these subgroups were confronted. Only MMP-3 levels significantly differed (Table 4, Table 5). According to the
Spearman correlation coefficient, there was a significant association between MMP-3 levels and SYNTAX score for the entire patient group $(0.358, \mathrm{a}=0.05)$ as well as for diabetic $(0.378, \mathrm{a}=0.05)$ and non-diabetic $(0.335, \mathrm{a}=0.05)$ subgroups. There was no significant correlation between SYNTAX score and the other investigated biomarkers.

\section{DISCUSSION}

The SYNTAX score is an angiographic grading tool to determine the functional complexity of coronary artery disease. It was derived from preexisting classifications and was published in 2005 (ref. ${ }^{4}$ ). This algorithm was developed for purposes of SYNTAX trial (Synergy Between Percutaneous Coronary Intervention With TAXUS and Cardiac Surgery) and provides the first evidence-based approach to employing optimal revascularization strategies for patients with three-vessel and/or left main coronary artery disease. In principle, the SYNTAX score is the sum of the points assigned to each individual lesion identified in the coronary tree with $>50 \%$ diameter narrowing in vessels $>1.5 \mathrm{~mm}$ diameter. The percent diameter stenosis is not a consideration, only the presence of a stenosis from $50-99 \%$ diameter, $<50 \%$ diameter narrowing or total occlusion.

The latest publications are indicative of new applications of this algorithm: a SYNTAX score of $>34$ also identifies a subgroup with a particularly high risk of cardiac death, independent of age, gender, acute coronary syndrome, ejection fraction, EUROscore and degree of revascularization ${ }^{5}$. Higher SYNTAX scores are predictive of peri-procedural myocardial injury during percutaneous coronary intervention ${ }^{6}$. In this study the SYNTAX score was used for description of coronary artery impairment enabling statistical processing.

Coronary artery disease is widely recognized as an inflammatory disease. Monocyte chemoattractant protein-1 (MCP-1) - alternative name chemokine (C-C motif) ligand 2 (CCL2), is a chemokine involved in the pathogenesis of atherosclerosis. By its chemotactic activity, it causes diapedesis of monocytes from the lumen to the subendothelial space where they become foam cells, initiating fatty streak formation that leads to atherosclerotic plaque formation. Inflammatory macrophages probably play a role in plaque rupture and the resulting ischaemic episodes as well as restenosis after angioplasty. There is strong evidence that $M C P-1$ plays a major role in myocarditis, ischaemia/reperfusion injury to heart and in transplant rejection ${ }^{7}$. During the early phase of acute myocardial infarction, the plasma levels of $M C P-1$ were significantly higher in patients with well-developed collateral circulation than patients with absent collateral circulation. These findings suggest that the shear stress-induced overexpression of $M C P-1$ contributes significantly to the development of coronary collaterals during the early phase of acute myocardial infarction ${ }^{8}$. In middle-aged overweight/ obese individuals $M C P-1$ was independently associated with CVD mortality ${ }^{9}$. Even though a promising biomar- 
Table 1. Baseline characteristics.

\begin{tabular}{|c|c|c|c|c|}
\hline & & $\begin{array}{l}\text { Diabetics }^{1} \\
(\mathrm{~N}=\mathbf{8 8})\end{array}$ & $\begin{array}{l}\text { Non-diabetics }{ }^{1} \\
\qquad(\mathrm{~N}=\mathbf{4 0})\end{array}$ & $\mathbf{p}^{2}$ \\
\hline \multirow{2}{*}{ 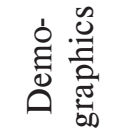 } & Age (years) & $64.0(48.0 ; 80.0)$ & $61.0(37.0 ; 79.0)$ & 0.571 \\
\hline & Male & $80.7 \%$ & $62.5 \%$ & $0.046^{*}$ \\
\hline \multirow{7}{*}{$\frac{v}{n} \stackrel{0}{0}$} & Weight (kg) & $88.9(68.0 ; 114.0)$ & $80.0(60.0 ; 115.0)$ & 0.138 \\
\hline & Body mass index & $29.7(25.0 ; 37.2)$ & $28.7(22.9 ; 36.2)$ & 0.223 \\
\hline & Waist (cm) & $101.0(88.0 ; 119.0)$ & $100.0(81.0 ; 120.0)$ & 0.154 \\
\hline & Former smoker & $33.0 \%$ & $22.5 \%$ & 0.298 \\
\hline & Current smoker & $12.5 \%$ & $10.0 \%$ & 0.775 \\
\hline & Metabolic syndrom & $95.5 \%$ & $50.0 \%$ & $<0.001 *$ \\
\hline & History of hypertension & $98.9 \%$ & $85.0 \%$ & $0.004 *$ \\
\hline \multirow{4}{*}{ 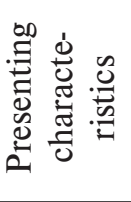 } & Systolic blood pressure (mm Hg) & $140.0(120.0 ; 180.0)$ & $146.0(100.0 ; 184.0)$ & 0.868 \\
\hline & Diastolic blood pressure ( $\mathrm{mm} \mathrm{Hg}$ ) & $70.0(56.0 ; 90.0)$ & $70.0(50.0 ; 90.0)$ & 0.601 \\
\hline & Left ventricular ejection fraction (\%) & $60.0(45.0 ; 65.0)$ & $60.0(35.0 ; 65.0)$ & 0.986 \\
\hline & SYNTAX score & $9.0(0.0 ; 30.5)$ & $2.0(0.0 ; 35.5)$ & $<0.001 *$ \\
\hline \multirow{12}{*}{ 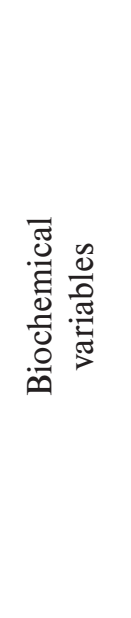 } & Total cholesterol (mmol/1) & $4.0(3.1 ; 6.4)$ & $4.8(3.3 ; 7.0)$ & $<0.001^{*}$ \\
\hline & LDL cholesterol (mmol/l) & $2.1(1.3 ; 3.9)$ & $3.0(1.5 ; 4.9)$ & $<0.001 *$ \\
\hline & HDL cholesterol (mmol/1) & $1.0(0.7 ; 1.4)$ & $1.1(0.7 ; 1.4)$ & 0.057 \\
\hline & Triglycerides (mmol/1) & $1.7(0.8 ; 3.9)$ & $1.3(0.7 ; 2.2)$ & $0.023^{*}$ \\
\hline & ApoB/ApoA1 & $0.6(0.4 ; 0.9)$ & $0.6(0.4 ; 1.0)$ & $0.038^{*}$ \\
\hline & Fasting glycaemia (mmol/1) & $7.5(5.2 ; 14.2)$ & & \\
\hline & Glycated haemoglobin HbA1c (\%) & $5.5(3.8 ; 8.6)$ & & \\
\hline & C-reactive protein (mg/l) & $2.4(0.4 ; 10.1)$ & $2.0(0.2 ; 7.1)$ & 0.710 \\
\hline & MCP-1 (ng/1) & $304.0(135.0 ; 625.0)$ & $369.4(0.0 ; 548.0)$ & $0.045^{*}$ \\
\hline & MMP-3 ( $\mu \mathrm{g} / 1)$ & $37.0(13.7 ; 82.5)$ & $25.8(11.9 ; 82.8)$ & $0.044^{*}$ \\
\hline & $\mathrm{sCD} 40 \mathrm{~L}(\mu \mathrm{g} / \mathrm{l})$ & $11.7(4.6 ; 21.3)$ & $9.9(5.8 ; 17.5)$ & 0.353 \\
\hline & sTNFR2 $(\mu \mathrm{g} / 1)$ & $1.3(0.0 ; 2.3)$ & $1.2(1.0 ; 2.4)$ & 0.871 \\
\hline
\end{tabular}

LDL, high density lipoprotein, HDL, high density lipoprotein, MCP-1, macrophage chemoattractant protein-1; MMP3, matrix-metalloproteinase-3; sCD40L, soluble CD40 ligand; sTNFR2, soluble tumour necrosis factor receptor-2

${ }^{1}$ Continuous variables were described using median and $5-95^{\text {th }}$ percentile; categorical variables are described using percentage of categories

${ }^{2}$ Statistical significance of differences in continuous variables between groups of patients was analysed by means of Mann - Whitney U test; statistical significance of relationship between binary variables was analysed using Fisher exact test; $\alpha=0.05$ was adopted as a level of significance for all tests and statistically significant results are given in bold and denoted by *

ker of atherosclerosis, we have not succeeded in confirming an association between circulating MCP-1 level and SYNTAX score.

It has become clear that the extracellular matrix is not a mere scaffold for cells but that it also has cryptic biological functions that can be revealed on proteolysis. Matrix metalloproteinases (MMPs) are a family of 24 zinc-dependent endopeptidases hydrolyzing components of the extracellular matrix ${ }^{10}$. Tissue inhibitors of metalloproteinases (TIMPs) are their specific inhibitors that participate in controlling the local activities of MMPs in tissues ${ }^{11}$. A loss of activity control may result in diseases such as arthritis, cancer, nephritis, tissue ulcers, and fibrosis $^{12}$. The pathological effects of MMPs and TIMPs in cardiovascular disease involve vascular remodeling, atherosclerotic plaque instability ${ }^{13}$, and left ventricular remodeling after myocardial infarction ${ }^{14,15}$. Some studies with matrix-metalloproteinase-3 (stromelysin-1) show its prospective value. It has been demonstrated that plasma fluctuation in $M M P-3$ levels can be used as a supplementary independent predictor of cardiovascular events in patients with stable coronary artery disease ${ }^{16}$. MMP-3 is associated with left ventricular dysfunction, adverse left ventricular remodelling and prognosis after AMI ${ }^{17}$. MMP- 
Table 2. Treatment.

\begin{tabular}{|c|c|c|c|c|}
\hline & & $\begin{array}{l}\text { Diabetics }^{1} \\
(\mathrm{~N}=88)\end{array}$ & $\begin{array}{c}\text { Non-diabetics }^{1} \\
(\mathrm{~N}=40)\end{array}$ & $\mathrm{p}^{2}$ \\
\hline \multirow{4}{*}{ 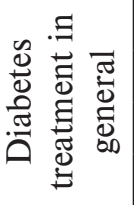 } & Diet & $39.8 \%$ & - & - \\
\hline & Diet + peroral antidiabetics & $44.3 \%$ & - & - \\
\hline & Insulin & $6.8 \%$ & - & - \\
\hline & Insulin + peroral antidiabetics & $8.0 \%$ & - & - \\
\hline \multirow{16}{*}{ 朐 } & Beta blockers & $68.2 \%$ & $67.5 \%$ & 0.990 \\
\hline & ACE inhibitors & $63.6 \%$ & $32.5 \%$ & $0.001^{*}$ \\
\hline & Angiotensin receptor blocker & $14.8 \%$ & $30.0 \%$ & 0.055 \\
\hline & Calcium antagonist & $38.6 \%$ & $10.0 \%$ & $0.001 *$ \\
\hline & Long-acting nitrate & $26.1 \%$ & $27.5 \%$ & 0.990 \\
\hline & Trimetazidin & $18.2 \%$ & $2.5 \%$ & $0.022 *$ \\
\hline & Acetylsalicylic acid & $85.2 \%$ & $65.0 \%$ & $0.018^{*}$ \\
\hline & Clopidogrel & $12.5 \%$ & $10.0 \%$ & 0.775 \\
\hline & Atorvastatin & $63.6 \%$ & $35.0 \%$ & 0.004* \\
\hline & Simvastatin & $15.9 \%$ & $10.0 \%$ & 0.426 \\
\hline & Other statin & $1.1 \%$ & $0.0 \%$ & 0.990 \\
\hline & Sulphonylurea derivates & $29.5 \%$ & $0.0 \%$ & $<0.001^{*}$ \\
\hline & Metformin & $45.5 \%$ & $0.0 \%$ & $<0.001^{*}$ \\
\hline & Acarbosis & $2.3 \%$ & $0.0 \%$ & 0.990 \\
\hline & Insulin & $10.2 \%$ & - & - \\
\hline & Insulin analogs & $4.5 \%$ & - & - \\
\hline
\end{tabular}

ACE, angiotensin-converting enzyme

${ }^{1}$ Categorical variables are described using percentage of categories

${ }^{2}$ Statistical significance of relationship between binary variables was analysed using Fisher exact test; $\alpha=0.05$ was adopted as a level of significance for all tests and statistically significant results are given in bold and denoted by *

3 together with B-type natriuretic peptide are significant independent predictors of cardiac events in patients with dilated cardiomyopathy. Patients with elevations of both were found to have the poorest prognosis ${ }^{18}$. The increased level of $M M P-3$ may be responsible for coronary artery ectasia formation ${ }^{19}$. Polymorphisms of MMP-3 and TIMP4 genes affect angiographic coronary plaque progression in non-diabetic and type 2 diabetic patients ${ }^{20}$.

Our findings show that circulating MMP-3 levels correlate with coronary artery disease presence (Table 5) and with SYNTAX score. Assuming that the SYNTAX score has the ability to describe anatomical and functional features of coronary artery disease, we suggest that MMP-3 levels can predict the extent of coronary artery impairment.

CD40 ligand (CD40L) and soluble CD40 ligand ( $s C D 40 L$ ) belong to the tumor necrosis factor superfamily, and they are molecules with a dual prothrombotic and proinflammatory role. They are expressed in a variety of tissues such as the immune system (in both B and T cells), the vascular wall, and activated platelets. Soluble CD $40 L$ has multiple autocrine, paracrine, and endocrine actions, and it may trigger the key mechanisms of atherothrombosis. CD40/CD40L may participate in the development of coronary atherosclerosis and triggering acute coronary syndromes while $s C D 40 L$ seems to have a prognostic role not only in people with advanced atherosclerosis but also in the general population ${ }^{21}$. It is hypothesized that sCD40L induces proliferation and migration of vascular smooth muscle cells through activation of matrix metalloproteinases $^{22}$. However the outcomes of studies with CD40L/sCD40L are inconsistent. sCD40L levels are elevated in hypertensive patients and might discriminate hypertensive patients at high risk of cardiovascular events as published by Ferroni et al. ${ }^{23}$. In contrast, another finding is that in newly diagnosed hypertensive men, $s C D 40 \mathrm{~L}$ levels are inversely related to insulin sensitivity, with no correlation with BP, other cardiovascular risk factors or degree of subclinical atherosclerosis ${ }^{24}$. In a TACTICSTIMI 18 trial, $s C D 40 L$ was not associated with risk in non-ST elevation acute coronary syndrome population treated with a platelet GPIIb/IIIa receptor antagonist ${ }^{25}$. It is known that atorvastatin diminishes $s C D 40 \mathrm{~L}$ plasma levels, more markedly in subjects with the metabolic syndrome ${ }^{26}$.

In general, preanalytic conditions are critical in the assessment of sCD40L concentrations. Some reports document the effects of specimen type (serum and 
Table 3. Gender variability of levels of selected biomarkers.

\begin{tabular}{|l|c|c|c|}
\hline & Male $^{1}(\mathbf{N}=96)$ & Female $^{1}(\mathbf{N}=32)$ & $\mathbf{p}^{2}$ \\
\hline MCP-1 & $321.0(132.0 ; 587.7)$ & $373.0(132.0 ; 625.0)$ & $\mathbf{0 . 0 1 7}^{*}$ \\
\hline MMP-3 & $42.1(15.7 ; 85.2)$ & $21.9(11.3 ; 44.8)$ & $\mathbf{< . 0 0 1 *}^{*}$ \\
\hline sCD40L & $11.7(5.2 ; 21.3)$ & $8.7(4.6 ; 17.3)$ & 0.054 \\
\hline sTNFR2 & $1.2(0.0 ; 2.1)$ & $1.4(0.8 ; 2.6)$ & $0.049^{*}$ \\
\hline
\end{tabular}

MCP-1, macrophage chemoattractant protein-1; MMP-3, matrix-metalloproteinase-3; sCD40L, soluble CD40 ligand; sTNFR2, soluble tumour necrosis factor receptor-2

${ }^{1}$ Continuous variables were described using median and $5-95^{\text {th }}$ percentile

${ }^{2}$ Statistical significance of differences in continuous variables between groups of patients was analysed by means of Mann - Whitney U test; $\alpha=0.05$ was adopted as a level of significance for all tests and statistically significant results are given in bold and denoted by *

Table 4. Coronary artery disease presence and level of selected biomarkers.

\begin{tabular}{|l|c|c|c|}
\hline & $\begin{array}{c}\text { CAD presence }^{1} \\
(\text { SYNTAX score }>\mathbf{0}) \\
(\mathbf{N = 1 0 4 )}\end{array}$ & $\begin{array}{c}\text { Without CAD } \\
\text { (core } \mathbf{~} \mathbf{0}) \\
(\mathbf{N = 2 4 )}\end{array}$ & $\mathbf{p}^{2}$ \\
\hline MCP-1 & $325.0(132.0 ; 625.0)$ & $369.0(165.0 ; 548.0)$ & 0.278 \\
\hline MMP-3 & $38.1(13.6 ; 84.1)$ & $20.4(13.1 ; 82.8)$ & $\mathbf{0 . 0 0 1}^{*}$ \\
\hline SCD40L & $11.6(5.2 ; 21.3)$ & $8.5(4.9 ; 18.8)$ & 0.307 \\
\hline STNFR2 & $1.3(0.0 ; 2.3)$ & $1.2(0.7 ; 1.9)$ & 0.270 \\
\hline
\end{tabular}

CAD, coronary artery disease; MCP-1, macrophage chemoattractant protein-1; MMP-3, matrix-metalloproteinase-3; sCD40L, soluble CD40 ligand; sTNFR2, soluble tumour necrosis factor receptor-2

${ }^{1}$ Continuous variables were described using median and $5-95^{\text {th }}$ percentile

${ }^{2}$ Statistical significance of differences in continuous variables between groups of patients was analysed by means of Mann - Whitney U test; $\alpha=0.05$ was adopted as a level of significance for all tests and statistically significant results are given in bold and denoted by *

Table 5. Coronary artery disease presence and according to level of MMP-3.

\begin{tabular}{|l|c|c|c|}
\hline \multicolumn{1}{|c|}{ MMP-3 } & $\begin{array}{c}\text { CAD presence } \\
\text { (SYNTAX score > 0) }\end{array}$ & $\begin{array}{c}\text { Without CAD } \\
\text { (SYNTAX score = 0) }\end{array}$ & $\mathbf{p}^{1}$ \\
\hline $1^{\text {st }}$ quartile $(\leq 21.9)$ & $58.1 \%$ & $41.9 \%$ & $\mathbf{0 . 0 0 6}^{*}$ \\
\hline $2^{\text {nd }}$ quartile $(22.0-35.4)$ & $83.3 \%$ & $16.7 \%$ & \\
\hline $3^{\text {rd }}$ quartile $(35.5-55.7)$ & $90.0 \%$ & $10.0 \%$ & \\
\hline $4^{\text {th }}$ quartile $(>55.7)$ & $90.0 \%$ & $10.0 \%$ & \\
\hline
\end{tabular}

MMP-3, matrix-metalloproteinase-3; CAD, coronary artery disease

${ }^{1}$ Statistical significance was analysed by means of ML Chi-square test; $\alpha=0.05$ was adopted as a level of significance for all tests and statistically significant results are given in bold and denoted

plasma), processing (time and temperature), and commercial reagent selection on $\mathrm{sCD} 40 \mathrm{~L}$ ELISA results ${ }^{27,28}$. High-sensitivity ELISA assay suitable for plasma and serum testing (Bender MedSystems) was used. In accordance with the recent manufacturer recommendations,we failed to confirm the association between sCD40L and SYNTAX score. The results can in part be affected by specimen type: in our study blood serum was tested. As for Halldorsdottir et al. the optimum strategy would be to measure sCD40L in platelet-free plasma ${ }^{28}$. Variability in statin administration could play its role as well (Table 2).

Tumor necrosis factor- $\alpha(\mathrm{TNF}-\alpha)$ is a pleiotropic cytokine involved in a broad spectrum of inflammatory and immune responses including proliferation, differentiation 
and cell death induction in several cell types. The biological effects of TNF- $\alpha$ are mediated via the cell-surface TNF- $\alpha$ receptors, TNFR1 and TNFR2. Upon activation, these two receptors are proteolytically cleaved from the membrane and shed into the circulation, where they can be measured as soluble forms (sTNFR1, sTNFR2). The level of sTNFR2 in the circulation could therefore be interpreted as the degree of activation of TNF- $\alpha$ signalling in the tissues, making sTNFR2 an interesting parameter for TNF- $\alpha$ activation in the tissues. High levels of sTNFR2 in serum have been documented in multiple inflammatory pathologies $^{29,30}$. Metabolic syndrome and diabetes are also associated with higher plasma concentrations of TNFalpha and its receptors ${ }^{31}$.

Our findings do not show any correlation between sTNFR2 level and coronary artery disease described by SYNTAX score. This result in high probability is not related to laboratory assay. Preanalytic conditions were kept precisely according to the manufacturer recommendations. The explanation can theoretically be in the patient selection - all individuals according to anamnesis, objective examination and laboratory methods had stable atherosclerotis plaques. Presence of unstable plaques could be an important cause of circulating sTNFR2 level elevation. However contrary to this theory is the finding of Mizia-Stec et al. ${ }^{32}$. According to their study in patients with stable coronary artery disease, interventional procedures result in suppression of sTNFR2 ${ }^{32}$. Other studies for clarifying of sTNFR2 consequences are needed.

According to our findings the concentrations of circulating MCP-1 and MMP-3 significantly differ between men and women. The difference is also seen in sTNFR2 and $\mathrm{sCD} 40 \mathrm{~L}$ levels, however the statistical significance is not so strong (Table 3 ). Several physiological conditions might explain this variability. It is assumed that markers of inflammation strongly correlate with measures of adiposity, and this association is generally stronger in women than in men ${ }^{33,34}$. The second potentially important aspect may involve differences in endogenous sex hormone levels or sex hormone-binding globulin ${ }^{35,36}$.

The main limitation of this study seems to be the coronary lesion significance assessment. The SYNTAX score considers over $50 \%$ coronary artery luminal reduction. The generally used estimation of luminal reduction is not exact and can be incorrect in spite of investigator experience. On the other hand, quantitative coronary analysis of the whole coronary bloodstream would have been exceedingly time consuming. Moreover, in the case of diffusely diseased arteries, it can be difficult to find the reference diameter. An intravascular imaging technique could enable precise stenosis quantification. The functional status could be described by fraction flow reserve determination. Using these methods any scoring system can become exact but useless for day-to-day routine.

Another limitation can be spuning of blood samples at room temperature. Using of cooled centrifuge is regarded as the best way of manipulation with sample in preanalytic stage. However this practice was not recommended in the diagnostic set manufacturer recommendations.

\section{CONCLUSIONS}

Our results suggest that in patients with stable coronary artery disease, MMP-3 level correlates with the extent of coronary artery disease. No association between the other investigated biomarkers and grade of coronary artery disease was found.

\section{ACKNOWLEDGEMENTS}

The work was supported by a specific grant of the Czech Society of Cardiology. The authors declare that they have no competing interests.

\section{REFERENCES}

1. European detailed mortality database (DMDB). Copenhagen, WHO Regional Office for Europe, 2010.

2. Bastarrika G, Lee YS, Huda W, Ruzsics B, Costello P, Schoepf UJ. CT of coronary artery disease. Radiology 2009; 253(2):317-38.

3. Serruys PW, Morice MC, Kappetein AP, Colombo A, Holmes DR, Mack MJ, Ståhle E, Feldman TE, van den Brand M, Bass EJ, Van Dyck N, Leadley K, Dawkins KD, Mohr FW, for the SYNTAX Investigators. Percutaneous Coronary Intervention versus Coronary-Artery Bypass Grafting for Severe Coronary Artery Disease. N Engl J Med 2009; 360(10):961-972.

4. Sianos G, Morel MA, Kappetein AP, et al. The SYNTAX score: an angiographic tool grading the complexity of CAD. EuroInterv 2005; 1:219-227.

5. Valgimigli M, Serruys PW, Tsuchida K, et al. Cyphering the complexity of coronary artery disease using the syntax score to predict clinical outcome in patients with three-vessel lumen obstruction undergoing percutaneous coronary intervention. Am J Cardiol 2007; 99(8):1072-1081.

6. Van Gaal W, Ponnuthurai F, Selvanayagam J, Testa L, Porto I, Neubauer S, Banning A. The Syntax score predicts peri-procedural myocardial necrosis during percutaneous coronary intervention. Int J Cardiol 2009; 135(1):60-65.

7. Niu J, Kolattukudy PE. Role of $M C P-1$ in cardiovascular disease: molecular mechanisms and clinical implications. Clin Sci Lond 2009; 117(3):95-109.

8. Park HJ, Chang K, Park CS, Jang SW, Ihm SH, Kim PJ, Baek SH, Seung KB, Choi KB. Coronary collaterals: the role of $M C P-1$ during the early phase of acute myocardial infarction. Int J Cardiol 2008; 130(3),409-413.

9. Piemonti L, Calori G, Lattuada G, Mercalli A, Ragogna F, Garancini MP, Ruotolo G, Luzi L, Perseghin G. Association between plasma monocyte chemoattractant protein- $l$ concentration and cardiovascular disease mortality in middle-aged diabetic and nondiabetic individuals. Diabetes Care 2009; 32(11):2105-10.

10. Visse R, Nagase H. Matrix Metalloproteinases and Tissue Inhibitors of Metalloproteinases. Circ Res 2003; 92:827-839.

11. Brew K, Dinakarpandian D, Nagase H. Tissue inhibitors of metalloproteinases: evolution, structure and function. Biochim Biophys Acta 2000; 1477:267-283.

12. Woessner JF. The matrix metalloproteinase family. In: Parks WC, Mecham RP, eds. Matrix Metalloproteinases. San Diego, Calif: Academic Press 1998:1-13.

13. Galis ZS, Khatri JJ. Matrix metalloproteinases in vascular remodeling and atherogenesis: the good, the bad, and the ugly. Circ Res 2002; 90:251-262.

14. Creemers EE, Cleutjens JP, Smits JF, Daemen MJ. Matrix metalloproteinase inhibition after myocardial infarction: a new approach to prevent heart failure? Circ Res 2001; 89:201-210.

15. Spinale FG. Matrix metalloproteinases: regulation and dysregulation in the failing heart. Circ Res 2002; 90:520-530. 
16. Siminelakis S, Kotsanti A, Kolaitis N, Niokou D, Vlachou I, Dimakopoulos G, Papadopoulou C. Circulating matrix metalloproteinase-3 due to myocardial ischemia. The Heart Surgery Forum 2009;12(4):E230-234.Kelly D, Khan S, Cockerill G, Ng LL, Thompson M, Samani NJ, Squire IB. Circulating stromelysin-1 (MMP-3): a novel predictor of LV dysfunction, remodelling and all-cause mortality after acute myocardial infarction. Eur J Heart Fail 2008; 10(2):133-139.

17. Ohtsuka T, Nishimura K, Kurata A, Ogimoto A, Okayama H, Higaki J. Serum matrix metalloproteinase-3 as a novel marker for risk stratification of patients with nonischemic dilated cardiomyopathy. J Card Fail 2007; 13(9):752-758.

18. Dogan A, Tuzun N, Turker Y, Akcay S, Kaya S, Ozaydin M. Matrix metalloproteinases and inflammatory markers in coronary artery ectasia: their relationship to severity of coronary artery ectasia. Coron Artery Dis 2008;19(8):559-563.

19. Chen QJ, Lu L, Peng WH, Hu J, Yan XX, Wang LJ, Zhang Q, Zhang RY, Shen WF. Polymorphisms of MMP-3 and TIMP-4 genes affect angiographic coronary plaque progression in non-diabetic and type 2 diabetic patients. Clin Chim Acta 2009; 405(1-2):97103.

20. Antoniades C, Bakogiannis C, Tousoulis D, Antonopoulos AS, Stefanadis C. The CD40/CD40 ligand system: linking inflammation with atherothrombosis. J Am Coll Cardiol 2009; 54 (8):669677.

21. Chai H, Aghaie K, Zhou W. Soluble CD40 ligand induces human coronary artery smooth muscle cells proliferation and migration. Surgery 2009; 146(1):5-11.

22. Ferroni P, Guadagni F. Soluble CD $40 L$ and its role in essential hypertension: diagnostic and therapeutic implications. Cardiovasc Hematol Disord Drug Targets 2008; 8(3):194-202.

23. Penno G, Pucci L, Dell'Omo G, Lucchesi D, Miccoli R, Del Prato S, Solini A, Pedrinelli R. Soluble CD40 ligand levels in essential hypertensive men: evidence of a possible role of insulin resistance. Am J Hypertens 2009; 22(9):1007-1013.

24. Morrow DA, Sabatine MS, Brennan ML, de Lemos JA, Murphy SA, Ruff CT, Rifai N, Cannon CP, Hazen SL. Concurrent evaluation of novel cardiac biomarkers in acute coronary syndrome: myeloperoxidase and soluble CD40 ligand and the risk of recurrent ischaemic events in TACTICS-TIMI 18. Eur Heart J 2008 29(9):1096-1102.

25. Blanco-Colio LM, Martín-Ventura JL, de Teresa E, Farsang C, Gaw A, Gensini G, Leiter LA, Langer A, Martineau P, Egido J. Atorvastatin decreases elevated soluble CD $40 \mathrm{~L}$ in subjects at high cardiovascular risk. Atorvastatin on inflammatory markers study: a substudy of ACTFAST. Kidney International. Supplement 2008; 111:S60-63.

26. Weber M, Rabenau B, Stanisch M, Elsaesser A, Mitrovic V, Heeschen C, Hamm C. Influence of sample type and storage conditions on soluble CD40 ligand assessment. Clin Chem 2006; 52:888-891.

27. Halldórsdóttir AM, Stoker J, Porche-Sorbet R, Eby CS. Soluble CD40 Ligand Measurement Inaccuracies Attributable to Specimen Type, Processing Time, and ELISA Method. Clinical Chemistry 2005; 51:1054-1057.

28. Lainez B, Fernandez-Real JM, Romero X, Esplugue E, Cañete JD, Ricart W, Engel P. Identification and characterization of a novel spliced variant that encodes human soluble tumor necrosis factor receptor 2. International Immunology 2004; 16(1):169-177.

29. Plomgaard P, Nielsen AR, Fischer CP, Mortensen OH, Broholm C, Penkowa M, Krogh-Madsen R, Erikstrup C, Lindegaard B, Petersen AMW, Taudorf S, Pedersen BK. Associations between insulin resistance and TNF- $\alpha$ in plasma, skeletal muscle and adipose tissue in humans with and without type 2 diabetes. Diabetologia 2007; 50:2562-2571.

30. Safranow K, Dziedziejko V, Rzeuski R, Czyzycka E, Wojtarowicz A, Bińczak-Kuleta A, Jakubowska K, Olszewska M, Ciechanowicz A, Kornacewicz-Jach Z, Machaliński B, Pawlik A, Chlubek D. Plasma concentrations of TNF-alpha and its soluble receptors $S T N F R 1$ and $s T N F R 2$ in patients with coronary artery disease. Tissue Antigens 2009; 74(5):386-392.

31. Mizia-Stec K, Gasior Z, Zahorska-Markiewicz B, Holecki M, Kumor P. Inflammatory markers in a 2-year follow-up of coronary artery disease. Heart Vessels 2006; 21(5):302-308.

32. Thorand B, Baumert J, Döring A, Herder C, Kolb H, Rathmann W, Giani G, Koenig W. Sex differences in the relation of body composition to markers of inflammation. Atherosclerosis 2006; 184:216-224.

33. Cartier A, Cote M, Lemieux I, Peruss L, Tremblay A, Bouchard C, Despres JP. Sex differences in inflammatory markers: what is the contribution of visceral adiposity? Am J Clin Nutr 2009; 89:1307-1314.

34. Dign EL, Song Y, Malik VS, Liu S. Sex differences of endogenous sex hormones and risk of type 2 diabetes: a systematic review and meta-analysis. JAMA 2006; 295:1288-1299.

35. Wang M, Crisostomo PR, Markel TA, Wang Y, Meldrum DR. Mechanisms of Sex Differences in TNFR2-Mediated Cardioprotection. Circulation 2008; 118(suppl 1):S38-S45. 
